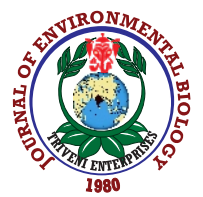

\title{
Germination indices of orthodox seeds as influenced by controlled deterioration and cathodic water seed invigoration
}

\author{
Kayode Fatokun ${ }^{1 *}$, R.P. Beckett ${ }^{2,3}$, Boby Varghese', Sershen ${ }^{4}$ and N.W. Pammenter \\ 'School of Life Sciences, University of KwaZulu-Natal Westville, Durban 4000, South Africa

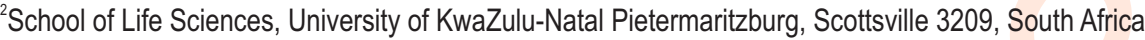 \\ ${ }^{3}$ Openlab "Biomarker", Kazan Federal University, Kazan 420008, The Republic of Tatarstan, Russia \\ ${ }^{4}$ South African Technology Network, La Lucia, Durban, 4321, South Africa
}

*Corresponding Author Email : kayfatokun@yahoo.com

\section{Abstract}

Aim : The aim of this study was to test the effects of priming on the germination of deteriorated orthodox seeds of five plant species.

\begin{abstract}
Methodology : The water content of seeds were raised to $14 \%$, and the seeds then deteriorated to $50 \%$ viability at $40^{\circ} \mathrm{C}$ and $100 \%$ relative humidity. Deteriorated seeds and fresh seeds of test species were then primed with cathodic water, un-electrophorized calcium magnesium solution and deionised water. Unprimed fresh and unprimed controlled deteriorated seeds served as controls. Germination indices were determined.
\end{abstract}

Results : In general, all priming treatments had positive effects on the germination indices of deteriorated seeds of all species, and a lesser extent on fresh seeds. However, seeds treated with cathodic water performed better than seeds treated with either CaMg solution or deionised water. While controlled deterioration reduced DNA concentrations and the DNA purity of seeds, priming, particularly with cathodic water had a protecting effect on DNA. Priming also boosted amylase activities in both fresh and deteriorated seeds.

Interpretation : Results are consistent with cathodic water reducing oxidative stress during imbibition. Cathodic water seed priming, therefore, has the potential to play a significant role in the conservation of orthodox seeds.

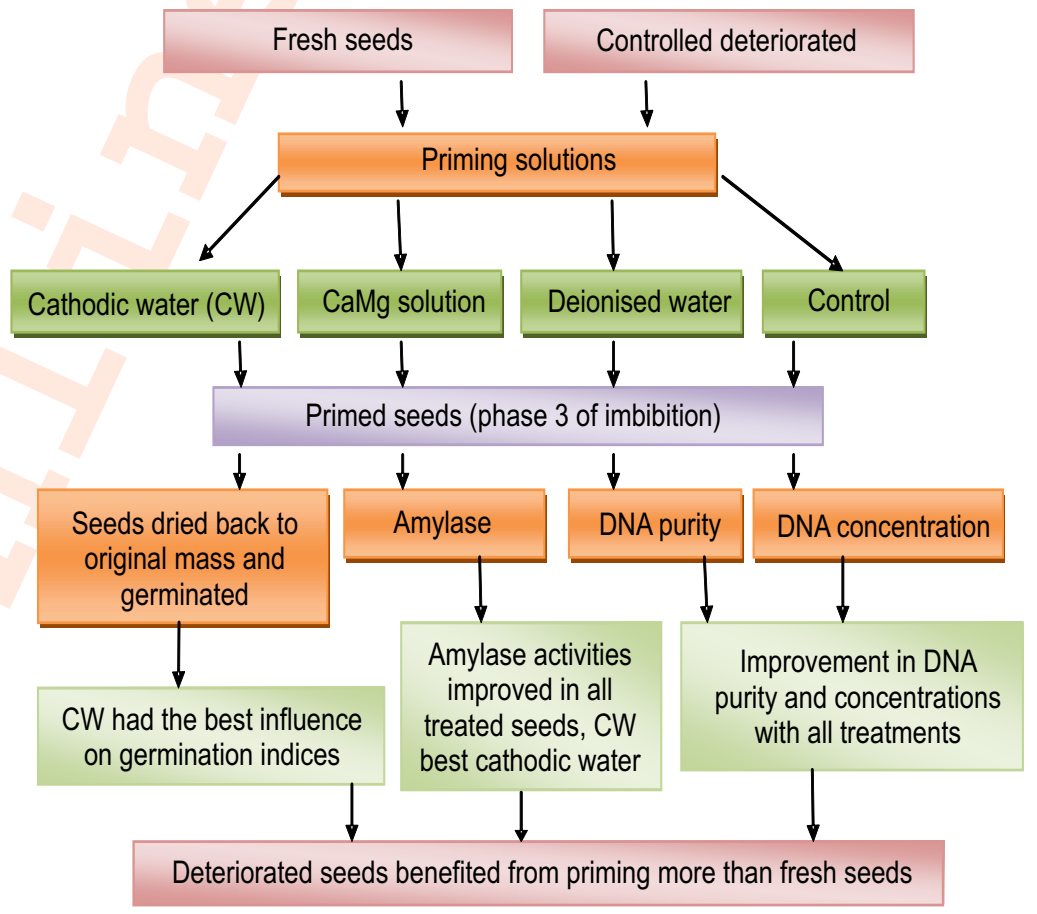

Key words: Cathodic water, Germination, Orthodox seeds, Pisum Sativum, Priming

How to cite : Fatokun Kayode, R.P. Beckett, Boby Varghese, Sershen and N.W. Pammenter: Germination indices of orthodox seeds as influenced by controlled deterioration and cathodic water seed invigoration. J. Environ. Biol., 41, 1105-1111 (2020). 


\section{Introduction}

Plants produce seeds that are either "orthodox", which tolerate dehydration and can be stored dry, or "recalcitrant", which are damaged by loss of only a small amount of water and cannot be stored for practical purposes (Berjak and Pammenter, 2008). Orthodox seeds, and the genetic resources they contain, can be effectively conserved in seeds banks (Walters et al., 2005). However, during long-term storage, even under optimal conditions, orthodox seeds deteriorate. Deterioration of seeds during long-term storage is known as ageing, and during this process both germination and seedling vigour are gradually lost (Garza-Caligaris et al., 2012). Seed deterioration is of global concern with respect to long-term conservation of genetic diversity of both wild species and agricultural plants (Zhang et al., 2016). The major focus of long-term seed conservation has been on the critically endangered species (Raimondo, 2015). However, there is also an urgent need to conserve the genetic resources of species of "actual or potential economic concern". Preservation of genetic diversity of crop plants is essential for future breeding programs to produce varieties that perform well under future climate change scenarios, particularly in sub-Saharan Africa where the effects of climate change are likely to be severe (Jorgenson and Burns, 2007; FAO, 2018).

In seeds of many plants, a loss of vigour, indicated by a reduction in the rate of germination, often precedes a gradual or abrupt decline in viability during storage (Finch-Savage and Bassel, 2016). The main factors contributing to loss of vigour are storage time, relative humidity and temperature of the storage environment, mechanical damage, seed water content, presence of microflora and seed maturity (McDonald, 2004; Yari et al., 2011; Vijayakumar et al., 2019). The underlying cause of seed deterioration is unclear, but a major contributing factor is believed to be the production of reactive oxygen species (ROS), which can attack any biomolecule, and induce programmed cell death (Kranner et al., 2010), eg., ROS-mediated lipid peroxidation has now been accepted as a major cause for cellular damage in deteriorated seeds (Walters et al., 2005; Mahjabin and Abidi, 2015). Ultimately, DNA can be damaged, resulting in delay in cell division and germination (Berjak, 2006).

While a major cause of the inability of recalcitrant seeds to tolerate drying appears to be uncontrolled ROS production (Whitaker et al., 2010), orthodox seeds have internal mechanisms that reduce the damaging effect of ROS. Such systems include both ROS scavenging enzymes such as superoxide dismutase (SOD), peroxidases (POX) and catalases (CAT), and also non-enzymatic antoxidants such as ascorbate, glutathione and tocopherol (Berjak et al., 2011). As seeds are stored for a progressively longer period, these mechanisms start breaking down, and seeds begin to deteriorate. It has been suggested that one way of slowing the rate of deterioration would be to exogenously supply antioxidants such as ascorbic acid, however, success has been variable and some antioxidants are cytotoxic at high concentration (Lehner et al., 2008; Berjak et al.,
2011). Recently, a novel approach that allows desiccation of embryonic axis of recalcitrant seeds has been described, involving treatment with "cathodic water" (Berjak et al., 2011; Naidoo et al., 2010). Cathodic water is a powerful antioxidant, and is the cathodic fraction of an electrolysed, dilute ionic solution of calcium and magnesium solution. A preliminary report suggests that treatment with cathodic water may improve the subsequent storage of orthodox seeds (Gondwe et al., 2016). However, it is unclear whether cathodic water can invigorate deteriorated orthodox seeds. Therefore, the aim of the present study was to test whether cathodic water can improve the vigour of deteriorated orthodox seeds of agricultural (Pisum sativum and Cucurbita pepo) and wild (Bolusanthus speciosus, Combretum erythrophyllum and Erythrina caffra) plants.

\section{Methods and Materials}

Plant materials: Seeds of five orthodox species were acquired from local seed companies around South Africa. The agricultural plants selected for the study were Pisum sativum L. (pea) and Cucurbita pepo L. (pumpkin), while the wild species included Bolusanthus speciosus (Bolus), Harms (tree wisteria), Combretum erythrophyllum (Burch.), Sond (River bush willow) and Erythrina caffra Thumb. All seeds were stored in airtight containers at $4^{\circ} \mathrm{C}$ until further use. Wild species had seed coatinduced or "physical" dormancy and therefore, the seed coats of $B$. speciosus and $E$. caffra were mechanically scarified, and the samara covering the seeds of Co. erythrophyllum were excised. Seeds of similar size were selected for further study.

Controlled deterioration of seeds: The initial water contents of the test species were determined gravimetrically. Using a water chamber, the water content of seeds were raised to $14 \%$, after which the seeds were subjected to controlled deterioration at $40^{\circ} \mathrm{C}$ and $100 \%$ relative humidity in a digital oven (Series 2000 , Scientific, USA). Seeds were sampled from the oven at 4 day interval and germination was tested until complete loss of germination occurred. The time required for $50 \%$ inhibition of germination was estimated $\left(P_{50}\right)$, and the process was repeated to confirm the repeatability of the estimation. Seeds aged to $P_{50}$ were used for further study.

Preparation of calcium-magnesium solution and cathodic water: A calcium-magnesium solution $(\mathrm{CaMg})$ of $0.5 \mu \mathrm{M} \mathrm{CaCl}_{2}$ and $0.5 \mathrm{mM} \mathrm{MgCl}$ was prepared. The CaMg solution was autoclaved for sterilization and stored in a refrigerator. When required, $200 \mathrm{ml}$ of CaMg solution was decanted into two glass beakers, and then platinum electrodes were immersed in the solutions, anode in one beaker and cathode in another. The circuit was completed with an agar-based salt bridge, and the solution was electrolysed at $60 \mathrm{~V}$ potential difference using a Bio-Rad PowerPac $^{\mathrm{TM}}$ Basic (Bio-Rad, USA) power pack for $1 \mathrm{hr}$ at room

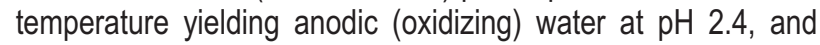
cathodic (reducing) water at pH 11.2 (Berjak et al., 2011). The anodic water was discarded whereas cathodic water was used within $1 \mathrm{hr}$. 
Seed priming: Three priming solutions used were cathodic water, CaMg solution and deionized water. Seeds were hydrated by placing them between 20 layers of single-ply paper towel, which was placed on aluminium foil. To prime the seeds, either 50 $\mathrm{ml}$ (for P. sativum, Cu. pepo and E. caffra) or $30 \mathrm{ml}$ (for $B$. speciosus and Co. erythrophyllum) of solutions were added. The seeds were hydrated in the priming solutions for $24 \mathrm{hr}$ ( $P$. sativum and Cu. pepo), $48 \mathrm{hr}$ (Co. erythrophyllum) or $18 \mathrm{hr}$ (E. caffra and $B$. speciosus), corresponding to a point close to, but just before the emergence of radicle. After hydration, the seeds were dried back to their original masses under ambient laboratory conditions for 7 ( $P$. sativum and Cu. pepo), 6 (E. caffra), 5 (Co. erythrophyllum) or 4 days (B. speciosus). The seeds were kept in air-tight bottles is a refrigerator until further use.

Determination of DNA purity and amylase activity: DNA was extracted at the end of phase 2 from seeds hydrated in priming solutions (cathodic water, calcium magnesium solution and deionised water). Briefly, seeds were ground into a fine powder ("seed meal") and approximately $70 \mathrm{mg}$ of powdered seeds were transferred in to a $1.5 \mathrm{ml}$ Eppendorf tubes containing $700 \mu \mathrm{l}$ of extraction buffer. The tubes were incubated for $10 \mathrm{~min}$ at $65^{\circ} \mathrm{C}$, and then $200 \mu \mathrm{l}$ of $5 \mathrm{M}$ potassium acetate was added. Tubes were vortexed, stored in ice for $10 \mathrm{~min}$, and then centrifuged at 12000 rpm for $10 \mathrm{~min}$ at $4^{\circ} \mathrm{C}$. Supernatant $(400 \mu \mathrm{l})$ was transferred into a new tube and $400 \mu$ l of iso-propyl alcohol was added. The supernatant was discarded and the pellets were washed twice with $500 \mu$ lethanol, centrifuging at $8000 \mathrm{rpm}$ for $3 \mathrm{~min}$ for each wash. The pellets were then dried at room temperature, resuspended in $50-100 \mu$ l of deionized water and stored at $-40^{\circ} \mathrm{C}$. The concentration and purity of DNA was read with Multiskan Sky NanoDrop $^{\mathrm{TM}}$ Spectrophotometer (Thermo Fisher Scientific, Wilmington, Delaware USA). P. sativum and Cu. pepo were selected to investigate the effect of priming on amylase activity. The seeds were hydrated in the priming solution until the beginning of phase 3 . Thereafter, $1 \mathrm{~g}$ was homogenized with 10 $\mathrm{ml}$ of ice cold $10 \mathrm{mM} \mathrm{CaCl}_{2}$ solution and amylase activity was estimated following the method of Devi et al. (2014).

Seed germination: Germination was tested at $25^{\circ} \mathrm{C}$ using $16 \mathrm{hr}$ light / $8 \mathrm{hr}$ dark cycle. Seeds were placed in $90 \mathrm{~mm}$ Petri dishes with five layers of moist germination paper under neath and another layer on top. Each treatment comprised 100 seeds divided in four replicates of 25 seeds arranged in a randomized design. Each replicate of 25 seeds was separated into five Petri dishes with five seeds per Petri dish to minimize competition between the seedlings. There were six seed priming treatments and two controls. The seed priming treatments were as follows: aged seeds primed with cathodic water (ASP.CW); aged seeds primed with CaMg solution (ASP.CM); aged seeds primed with distilled water (ASP.DW); fresh seed (unaged) primed with cathodic water (FSP.CW); fresh seeds primed with CaMg solution

Table 1: Effects of cathodic water, calcium magnesium solution and deionized water treatments on the germination parameters of five species of seeds. for first day of germination, a non-parametric Kruskal-Wallis rank sum test for multiple independent samples was carried out, followed by Dunn's post-hoc test. For other parameters, a standard ANOVA was carried out, followed by Tukey's post-hoc test. Means along the same row with different letters were significantly different

\begin{tabular}{|c|c|c|c|c|c|c|c|c|c|c|}
\hline \multirow{2}{*}{ Germination indices } & \multicolumn{4}{|c|}{ Fresh seeds } & \multirow[b]{2}{*}{ ASC } & \multirow[b]{2}{*}{ ASP.CW } & \multicolumn{4}{|c|}{ Controlled deteriorated seeds } \\
\hline & FSC & FSP.CW & FSP.CM & FSP.DW & & & ASP.CM & ASP.DW & $\mathrm{LSD}_{0.05}$ & $\operatorname{SE}(+)$ \\
\hline \multicolumn{11}{|l|}{ Bolusanthus speciosus } \\
\hline First day of germination & $3^{\mathrm{a}}$ & $3^{\mathrm{a}}$ & $3^{\mathrm{a}}$ & $3^{\mathrm{a}}$ & $5^{\mathrm{bc}}$ & $4^{b}$ & $4^{b}$ & $4^{b}$ & 0 & 0 \\
\hline Germination percentage & $98^{d}$ & $100^{d}$ & $100^{\mathrm{d}}$ & $99^{d}$ & $52^{\mathrm{a}}$ & $79^{c}$ & $69^{b}$ & $69^{b}$ & & 52 \\
\hline Germination index & $18.9^{d}$ & $26.7^{\dagger}$ & $23.3^{\mathrm{e}}$ & $22.2^{\mathrm{e}}$ & $5.5^{\mathrm{a}}$ & $14.3^{\mathrm{c}}$ & $10.8^{\mathrm{b}}$ & $9.4^{b}$ & 1.0 & 0.5 \\
\hline \multicolumn{11}{|c|}{ Combretum erythrophyllum } \\
\hline First day of germination & $11^{a}$ & $11^{\mathrm{a}}$ & $11^{\mathrm{a}}$ & $11^{\mathrm{a}}$ & $13^{c}$ & $12^{\mathrm{b}}$ & $12^{\mathrm{b}}$ & $12^{\mathrm{b}}$ & 0 & 0 \\
\hline Germination percentage & $83^{\mathrm{c}}$ & $91^{\circ}$ & $86^{c}$ & $82^{c}$ & $47^{\mathrm{a}}$ & $66^{\mathrm{b}}$ & $55 a^{b}$ & $56 \mathrm{a}^{\mathrm{b}}$ & 9 & 5 \\
\hline Germination index & $7.4^{\circ}$ & $9.5^{\mathrm{d}}$ & $7.9^{\circ}$ & $7.6^{\mathrm{c}}$ & $2.8^{\mathrm{a}}$ & $4.5^{\mathrm{b}}$ & $4.2^{\mathrm{b}}$ & $4.0 \mathrm{a}^{\mathrm{b}}$ & 0.8 & 0.4 \\
\hline \multicolumn{11}{|l|}{ Erythrina caffra } \\
\hline First day of germination & $3^{\mathrm{a}}$ & $3^{\mathrm{a}}$ & $3^{\mathrm{a}}$ & $3^{\mathrm{a}}$ & $5^{\mathrm{bc}}$ & $4^{b}$ & $4^{b}$ & $4^{b}$ & 0 & 0 \\
\hline Germination percentage & $99^{d}$ & $100^{d}$ & $99^{d}$ & $100^{d}$ & $51^{\mathrm{a}}$ & $77^{\circ}$ & $69^{\text {bc }}$ & $65^{b}$ & 5 & 3 \\
\hline Germination index & $23.2^{\mathrm{d}}$ & $27.4^{f}$ & $25.4^{\mathrm{e}}$ & $25.3^{\mathrm{e}}$ & $6.0^{\mathrm{a}}$ & $11.7^{\circ}$ & $10.4^{\mathrm{bc}}$ & $9.4^{\mathrm{b}}$ & 0.9 & 0.5 \\
\hline \multicolumn{11}{|l|}{ Pisum sativum } \\
\hline First day of germination & $3^{\mathrm{a}}$ & $3^{\mathrm{a}}$ & $3^{\mathrm{a}}$ & $3^{\mathrm{a}}$ & $5^{\mathrm{bc}}$ & $4^{b}$ & $4^{b}$ & $4^{b}$ & 0 & 0 \\
\hline Germination percentage & $99^{d}$ & $100^{d}$ & $99^{d}$ & $99^{d}$ & $52^{\mathrm{a}}$ & $81^{\circ}$ & $75 b^{b c}$ & $71^{b}$ & 5 & 2 \\
\hline Germination index & $22.2^{\mathrm{d}}$ & $29.4^{\dagger}$ & $26.2^{\mathrm{e}}$ & $24.8^{\mathrm{e}}$ & $7.3^{\mathrm{a}}$ & $16.5^{\mathrm{c}}$ & $13.0^{\mathrm{b}}$ & $11.9^{\mathrm{b}}$ & 1.0 & 0.5 \\
\hline \multicolumn{11}{|l|}{ Cucurbita pepo } \\
\hline First day of germination & $4^{a}$ & $4^{a}$ & $4^{\mathrm{a}}$ & $4^{\mathrm{a}}$ & $7^{\circ}$ & $5^{\mathrm{b}}$ & $5^{\mathrm{b}}$ & $5^{\mathrm{b}}$ & 0 & 0 \\
\hline Germination percentage & $100^{d}$ & $100^{d}$ & $99^{d}$ & $99^{d}$ & $52^{\mathrm{a}}$ & $85^{\circ}$ & $71^{b}$ & $67^{b}$ & 6 & 3 \\
\hline Germination index & $0.033^{\mathrm{d}}$ & $0.055^{9}$ & $0.048^{f}$ & $0.044^{e}$ & $0.018^{\mathrm{a}}$ & $0.029^{\circ}$ & $0.024^{b}$ & $0.023^{b}$ & 0.002 & 0.001 \\
\hline
\end{tabular}




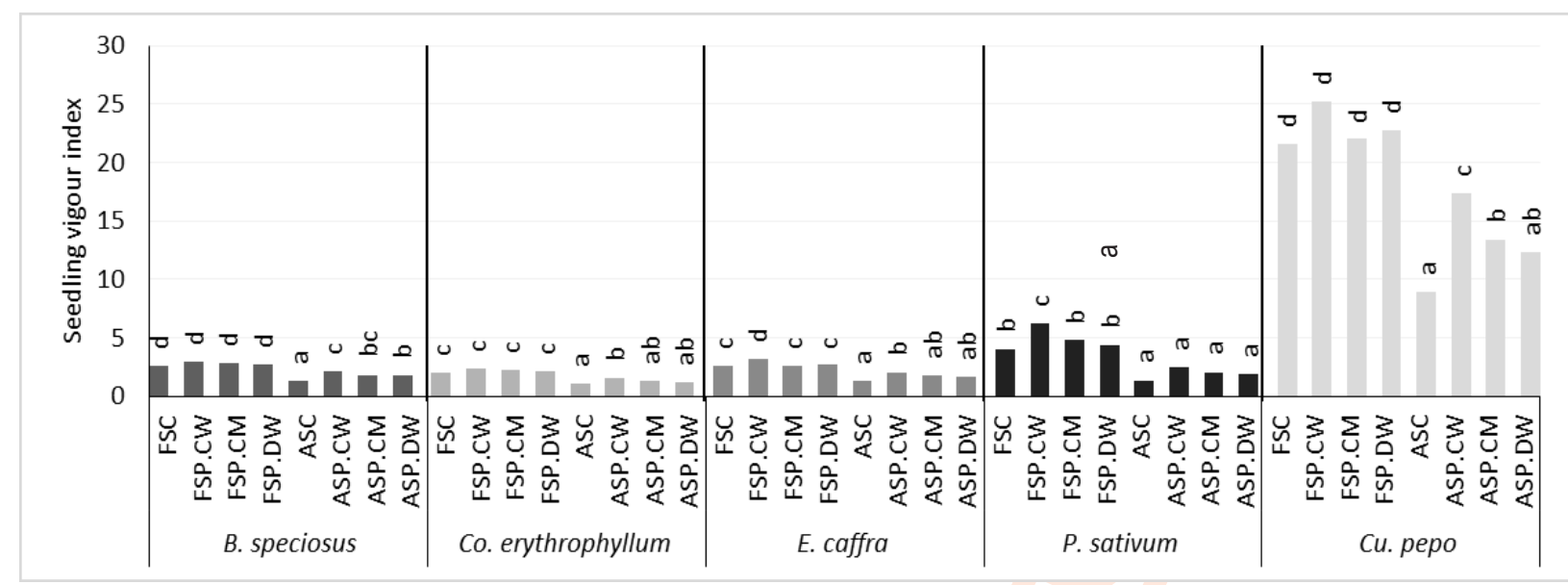

Fig. 1: Effects of controlled deterioration of seeds and seed priming with cathodic water, $\mathrm{Ca} \mathrm{Mg}$ solution and deionized water treatments on the seedling vigour of five plant species that produce orthodox seeds. In this and the Figures that follow, FSC are fresh seeds that were neither deteriorated or primed, FSP.CW are fresh seeds primed with cathodic water, FSP.CM are fresh seeds primed with CaMg solution, FSP.DW are fresh seeds primed with distilled water, ASC are seeds deteriorated and not primed, ASP.CW are deteriorated seeds that were primed with cathodic water, ASP.CM aredeteriorated seeds primed with CaMg solution, and ASP.DW are deteriorated seeds primed with distilled water. In all Figures, means with different letters were significantly different.

(FSP.CM); and fresh seeds primed with distilled water (FSP.DW) The two controls were seeds that were first control deteriorated and unprimed (ASC) and the second fresh seeds that were neither deteriorated nor primed (FSC). A seed was considered germinated when $1 \mathrm{~mm}$ radicle protrusion was observed. Germination counts were taken once a day for $14 \mathrm{~d}$ for B. speciosus, E. caffra P. sativum and Cu. Pepo and $21 \mathrm{~d}$ for Co. erythrophyllum. First day germination (FDG), final germination percentage (FGP) and germination index $(\mathrm{Gl})$ were calculated following the method of Czabator (1962). At the end of germination study, five seedlings were randomly selected per replicate across all treatments and plant species, separated into root and shoot, oven dried at $65^{\circ} \mathrm{C}$ to constant mass and then weighed. In addition, seedlings' vigour index (SVI) was calculated by the formula SVI = DM $(\mathrm{g}) \times \mathrm{FGP}$, where DM is dry mass of seedling $(\mathrm{g})$ and FGP is final germination percentage (Abdul-Baki and Anderson, 1973)

Statistical analyses : The data collected were subjected to analysis of variance (ANOVA) using Genstat Release 12.1 (VSN International Ltd., 2009). The means of the treatments were separated by least significant difference at $5 \%\left(\mathrm{LSD}_{0.05}\right)$. Post-hoc analysis was performed by Tukey test. However, for the "first day of germination" data a non-parametric ANOVA (Kruskal-Wallis rank sum test for multiple independent samples) was used, followed by Dunn's post-hoc test adjusted by the BenjaminiHochberg FDR method.

\section{Results and Discussion}

Seeds stored under optimum conditions deteriorate with time, and seed banks need to regularly evaluate the quality by using germination indices (Kader, 2005; Abdolahi et al., 2012). The effects of seed deterioration to some extent can be reversed by using various priming methods, also known as seed invigoration (Amanpour-Balaneji et al., 2012; Sadeghi and Shekafandeh, 2016). The aim of the present study was to evaluate a novel method of invigoration using cathodic water; taken together, results strongly suggest that cathodic water has considerable potential for invigorating deteriorated seeds. In the present study, rather than using naturally aged seeds, seeds were subjected to controlled deterioration until they had lost $50 \%$ germination. In all species, controlled deterioration of seeds led to significant $(p<0.05)$ delay in germination and a reduction in the germination index, reflecting a reduction in germination rate (Table 1). Deterioration also reduced seedling vigour (Fig. 1) and biomass (Fig. 2), and the concentration and purity of DNA (Fig. 3.4). It seems likely that these changes are at least in part a result of accelerationin the accumulation of ROS that occurs during deterioration (Kranner et al., 2010). ROS can attack DNA, causing breakage of DNA strands and deoxyribose sugar and peroxidise membrane lipids (Suresh et al., 2019). Such oxidative damage inhibits mitosis (McDonald, 1999; Bailly, 2004), resulting in delayed germination and reduced seed vigour and seedling biomass (Suresh et al., 2019), as observed in this study.

Priming deteriorated seeds of all species with cathodic water, $\mathrm{CaMg}$ solution and deionized water significantly $(p<0.05)$ improved both the rate of germination and the final germination percentage compared with un-primed seeds (Table 1). Furthermore, in all species, cathodic water was more effective than $\mathrm{CaMg}$ or deionized water, although differences between priming treatments were only significant for $\mathrm{B}$. speciosus, $\mathrm{Cu}$. pepo (rate of germination and final germination percentage), and 


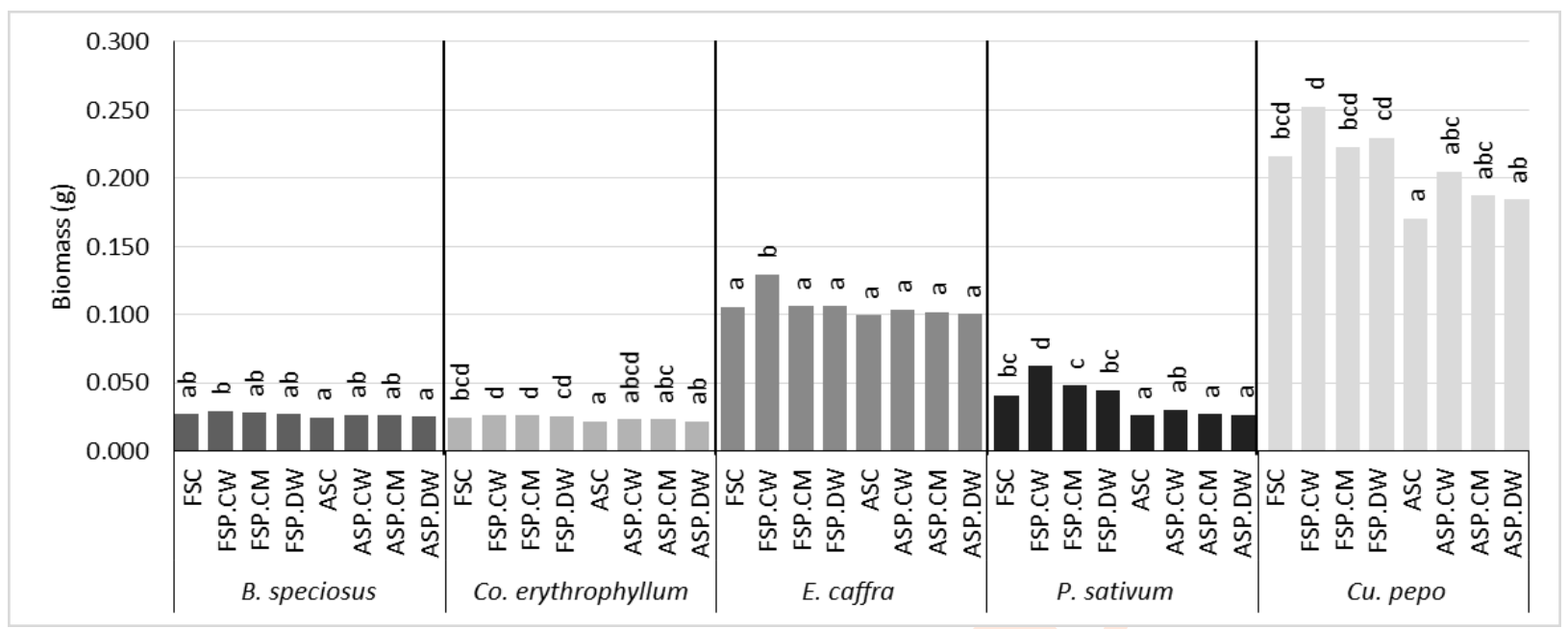

Fig. 2: Effects of controlled deterioration of seeds and seed priming with cathodic water, CaMg solution and deionized water on the biomass of seedlings of five plant species that produce orthodox seeds.

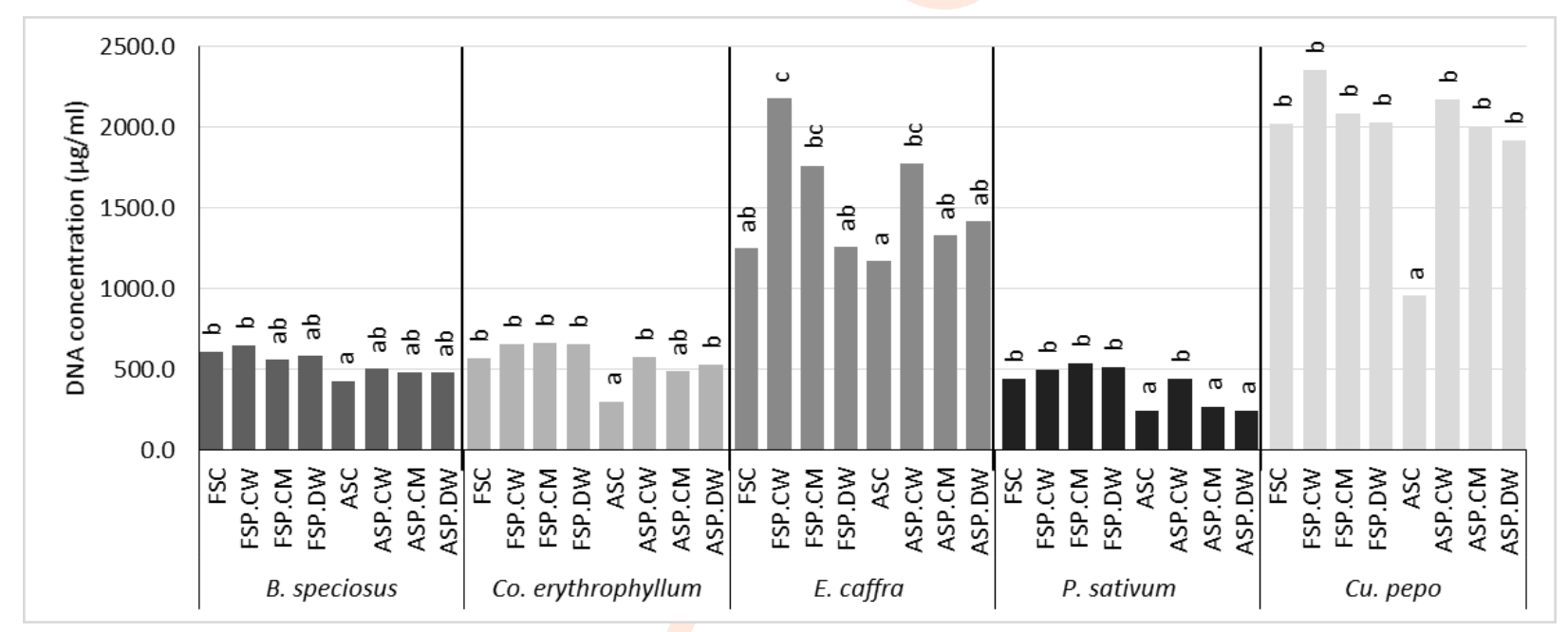

Fig. 3: Effects of controlled deterioration of seeds and seed priming with cathodic water, CaMg solution and deionized water on DNA concentration of orthodox seeds of five plant species.

P. sativum (rate of germination). Interestingly, cathodic water even increased the rate of germination in fresh seeds (Table 1), while other priming treatments had similar, but smaller effects. In all species, deterioration significantly $(p<0.05)$ reduced seedling vigour compared with fresh seed (Table 1). Cathodic water priming significantly improved seedling vigour in the deteriorated seeds of all species, except $P$. sativum, while priming with $\mathrm{CaMg}$ or distilled water was less effective (Fig. 1). Even in fresh seeds, cathodic water significantly improved vigour in $E$. caffra and $P$. sativum (Fig. 1). Effects of deterioration and priming on seedling dry mass were less pronounced (Fig. 2). In all species, controlled deterioration reduced the concentrations (Fig. 3) and purity (Fig. 4) of DNA in the seeds. A ratio of $\sim 1.8$ between $A_{260}$ and $A_{280}$ is generally accepted as normal for "pure" DNA. DNA extracted from all treatments of Co. erythrophyllum strongly deviated from normal values, suggesting that protein, phenol or other contaminants that absorb strongly at or near $280 \mathrm{~nm}$ were present (Khare et al., 2014). However, the decline in DNA concentrations and purity caused by deterioration were probably a result of breakage or damage of DNA strands, which is likely to cause 


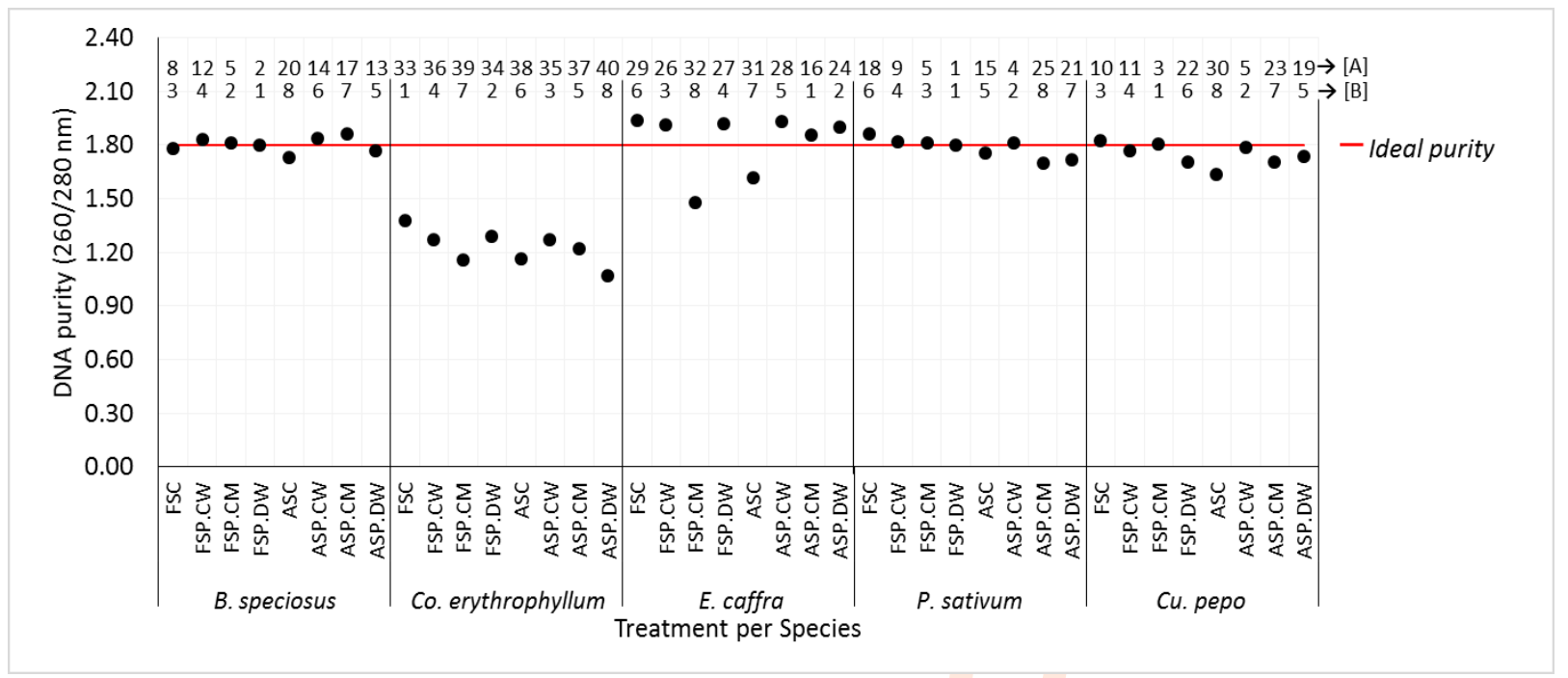

Fig. 4: Effects of controlled deterioration of seeds and seed priming with cathodic water, CaMg solution and deionized water on DNA purity from the orthodox seeds of five plant species $(n=3)$. A: Purity of all the five species were ranked from the most pure (1) to the least pure $(40)$. and B: Purity of each of the five species was ranked from the most pure (1) to the least pure (8).

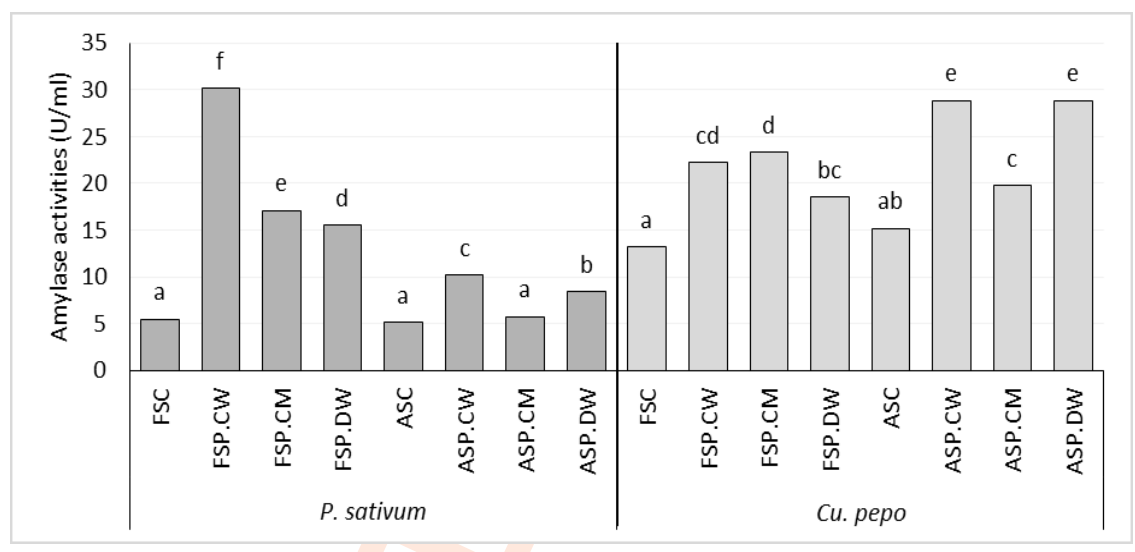

Fig. 5: Effects of controlled deterioration of seeds and seed priming with cathodic water, CaMg solution and deionized water on amylase activities of $P$. sativum and Cu. pepo seeds.

delay in mitosis (McDonald, 1999; Bailly, 2004). Delay in mitosis delays cell division, and consequently retards germination and reduces seed vigour and seedling biomass (McDonald, 1999; Bailly, 2004; Balestrazzi et al., 2011). In deteriorated seeds, priming increased both the amount and purity of DNA, and in most species cathodic water was most effective, often significantly so. The most likely explanation is that cathodic water reduced oxidative stress, reducing DNA damage during imbibition, improving the performance of primed deteriorated seeds.

Imbibition is known to trigger the release of gibberellins, which in turn stimulates synthesis of amylase (Damaris et al.,
2019), a key enzyme in germination. Amylase provides food materials for growth and development of germinating embryo by breaking down starch into low molecular mass carbohydrates that can be used for embryo growth. Deterioration had no significant effect on amylase activity in P. sativum and Cu. pepo (Fig. 5). However, in both species, priming with any of the solutions significantly $(p<0.05)$ increased amylase activities. In $P$. sativum, cathodic water increased amylase activity significantly more than the other two priming solutions, while in $\mathrm{Cu}$. pepo the $\mathrm{CaMg}$ solution was best for fresh seeds, while cathodic water and distilled water were best for deteriorated seeds. Stimulation of amylase activity by priming may in part contribute to the improved 
performance of primed seeds, particularly seeds primed with cathodic water. The study concludes that cathodic water seed priming has potential to play significant role in the conservation of orthodox seeds by reducing oxidative stress during imbibition.

\section{Acknowledgments}

The authors are grateful to the National Research Foundation of South Africa for sponsoring this project. We also thank all the research assistants of the Plant Germplasm Conservation Research Group of the University of KwaZuluNatal, Westville Campus, who assisted in the course of data collection. In addition, we thank the Russian Government Program of Competitive Growth of Kazan Federal University for partial financial support.

\section{References}

Abdollahi, M., S. Eshghi, E. Tafazzoli and N. Moosavi: Effects of paclobutrazol, boric acid and zinc sulfate on vegetative and reproductive growth of strawberry cv. Selva. J. Agri. Sci. Techn., 14,357-363 (2012).

Abdul-Baki, A.A. and J.D. Anderson: Vigor determination in soybean seed by multiple criteria. Crop Sci., 13, 630-633 (1973).

Amanpour-Balaneji, B. and M. Sedghi: Effect of aging and priming on physiological and biochemical traits of common bean (Phaseolus vulgaris L.). Notulae Scientia Biologicae, 4, 95-100 (2012).

Bailly, C.: Active oxygen species and antioxidants in seed biology. Seed Sci. Res., 14, 93-109 (2004).

Balestrazzi, A., M. Confalonieri, A. Macovei and D. Carbonera: Seed imbibition in Medicago truncatula Gaertn.: Expression profiles of DNA repair genes in relation to PEG-mediated stress. J. Plant Physio., 168, 706-713 (2011).

Berjak, P.: Unifying perspectives of some mechanisms basic to desiccation tolerance across life forms. Seed Sci. Res.,16, 1-15(2006).

Berjak P. and N.W.Pammenter: From Avicennia to Zizania: seed recalcitrance in perspective. Ann. Bot. London, 101, 213-228, (2008).

Berjak, P., Sershen, B. Varghese and N.W. Pammenter: Cathodic amelioration of oxidative stress accompanying procedures necessary for cryopreservation of embryonic axes of recalcitrantseeded species. Seed Sci. Res., 21, 187-203 (2011).

Czabator, F.J.: Germination value: An index combining speed and completeness of pine seed germination. Forest Sci., 8, 386-396 (1962).

Damaris, R.N., Z. Lin, P. Yang and D. He: The rice alpha-amylase, conserved regulator of seed maturation and germination. Int. $J$. Mol. Sci., 21, E450 (2019).

Devi, K., M. Sharma and P.S. Ahuja: Direct somatic embryogenesis with high frequency plantlet regeneration and successive cormlet production in saffron (Crocus sativus L.). South African J. Botany, 93, 207-216 (2014).

FAO: The State of Food Security and Nutrition in the World 2018. The Food and Agriculture Organization of the United Nations, Rome Italy (2018).

Finch-Savage, W. and G. Leubner-Metzger: Seed dormancy and the control of germination. The New Phytologist, 171, 501-523(2006).

Garza-Caligaris, L., A. Avendaño-Vázquez, S. Alvarado-López, E. Zúñiga-Sánchez, A. Orozco-Segovia, R. Pérez-Ruíz and A. Gamboa-Debuen: 'At3g08030 transcript: A molecular marker of seed ageing. Annals of Botany, 110, 1253-1260 (2012)

Gondwe, D., P. Berjak, N.W. Pammenter, S. Naidoo and B. Varghese: Effect of priming with cathodic water and subsequent storage on invigoration of Pisum sativum, Cucurbita maxima and Lycopersicon esculentum. Seed Sci. Tech., 44, 1-12 (2016).

Jorgenson, A. and T. Burns: Effects of rural and urban population dynamics and national development on deforestation in lessdeveloped countries 1990-2000. Sociological Inquiry, 77, 460-482 (2007).

Kader, A.: Comparison of seed germination calculation formulae and the associated interpretation of resulting Data. J. Proc. Royal Society New South Wales, 138, 65-75(2005).

Khare, P., V. Raj, S. Chandra and S. Agarwal: Quantitative and qualitative assessment of DNA extracted from saliva for its use in forensic identification. J. Forensic Dental Sci., 6, 81-85 (2014).

Kranner, I., T. Roach, R. Beckett, C. Whitaker and F. Minibayeva: Extracellular production of reactive oxygen species during seed germination and early seedling growth in Pisum sativum. J. Plant Physio., 167, 805-811 (2010).

Lehner, A., N. Mamadou, P. Poels, D. Côme, C. Bailly and F. Corbineau: Changes in soluble carbohydrates, lipid peroxidation and antioxidant enzyme activities in the embryo during ageing in wheat grains. J. Cereal Sci., 47, 555-565(2008).

Mahjabin, S.B. and A.B. Abidi: Research article physiological and biochemical changes during seed deterioration: Int. J. Recent Scie. Res., 6, 3416-3422 (2015).

McDonald, M.B.: Orthodox seed deterioration and its repair'. In: Handbook of Seed Physiology: Applications to Agriculture, (Eds.: Benech- R.L. Arnold and R.A. Sanchez). Food Products Press, New York, pp. 273-304 (2004)

McDonald, M.B: Seed deterioration: Physiology, repair and assessment. Seed. Sci. Tech., 27, 177-237 (1999).

Naidoo, S., N.W. Pammenter and P. Berjak: Effects of partial dehydration of recalcitrant Haemanthus montanus zygotic embryos on vigour of recovered seedlings. S. Afr. J. Bot., (2010). doi: 10.1016/j.sajb. 2010.07.015

Raimondo, D.: South Africa's Strategy for plant conservation. South African National Biodiversity Institute and the Botanical Society of South Africa, Pretoria (2015).

Sadeghi, F. and A. Shekafandeh: Seed priming effect on germination, seedling growth and salt tolerance of loquat (Eriobotrya japonica Lindl.). Albanian J. Agric. Sci.,10, 359-368, (2016).

Suresh A., N. Shah, M. Kotecha and P. Robin: Evaluation of biochemical and physiological changes in seeds of Jatropha curcas L. under natural ageing accelerated ageing and saturated salt accelerated ageing. Sci. Horticul., 255, 21-29 (2019).

Vijayakumar, H.P., A. Vijayakumar, P. Srimathi, G. Somasundaram, S.R. Prasad, S. Natarajan and K. Vishwanath: Correlation among physiological and histological changes in soybean seeds during storage. J. Environ. Bio., 40, 217-225 (2019).

Walters, C., L.M. Wheeler and J.M. Grotenhuis: Longevity of seeds stored in a genebank: Species characteristics. Seed Sci. Res., 15, 1-20 (2005).

Whitaker, C., R.P. Beckett, F.V. Minibayeva and I. Kranner: Production of reactive oxygen species in excised, desiccated and cryopreserved explants of Trichiliad regeana. SouthAfri. J. Bot., 76, 112-118(2010).

Yari L., F. Khazaei, H. Sadeghi and S. Sheidaei: Effect of seed priming on grain yield and yield components of bread wheat (Triticum aestivum L.), J. Agr. Biol. Sci., 6, 1-5 (2011).

Zhang, H., N. Mittal, L.J. Leamy, O. Barazani and B.H. Song: Back into the wild-apply untapped genetic diversity of wild relatives for crop improvement Evoluti. Appli., 10, 5-24 (2016). 